\section{(a) OPEN ACCESS}

\title{
COVID-19 in children treated with immunosuppressive medication for kidney diseases
}

\author{
Matko Marlais (1) , 1,2 Tanja Wlodkowski, ${ }^{3}$ Samhar Al-Akash, ${ }^{4}$ Petr Ananin, ${ }^{5}$ \\ Varun Kumar Bandi, ${ }^{6}$ Veronique Baudouin, ${ }^{7}$ Olivia Boyer, ${ }^{8}$ Luciola Vásquez, ${ }^{9}$ \\ Sukanya Govindan, ${ }^{10}$ Nakysa Hooman, ${ }^{11}$ Iftikhar ljaz, ${ }^{12}$ Reyner Loza, ${ }^{13}$ \\ Marta Melgosa, ${ }^{14}$ Nivedita Pande, ${ }^{15}$ Lars Pape, ${ }^{16}$ Anshuman Saha, ${ }_{1}^{17}$ \\ Dmitry Samsonov, ${ }^{18}$ Michiel F Schreuder, ${ }_{1}^{19}$ Jyoti Sharma, ${ }^{20}$ Sahar Siddiqui, ${ }^{21}$ \\ Rajiv Sinha, ${ }^{22}$ Heather Stewart, ${ }_{1}^{23}$ Velibor Tasic $\left(10,{ }^{24}\right.$ Burkhard Tönshoff, ${ }_{1}^{25}$ \\ Katherine Twombley, ${ }^{26}$ Kiran Upadhyay, ${ }^{27}$ Marina Vivarelli, ${ }^{28}$ Donald J Weaver, ${ }^{29}$ \\ Robert Woroniecki, ${ }^{30}$ Franz Schaefer, ${ }^{3}$ Kjell Tullus (i) ${ }^{2}$
}

For numbered affiliations see end of article.

Correspondence to Dr Matko Marlais, Institute of Child Health, University College London, London, UK: m.marlais@ucl.ac.uk

Received 3 September 2020 Revised 6 November 2020 Accepted 16 November 2020 Published Online First 21 December 2020

\section{Check for updates}

(c) Author(s) (or their employer(s)) 2021. Re-use permitted under CC BY-NC. No commercial re-use. See rights and permissions. Published by BMJ.

To cite: Marlais $\mathrm{M}$, Wlodkowski T, Al-Akash S, et al. Arch Dis Child 2021:106:798-801.

\section{ABSTRACT}

Background Children are recognised as at lower risk of severe COVID-19 compared with adults, but the impact of immunosuppression is yet to be determined. This study aims to describe the clinical course of COVID-19 in children with kidney disease taking immunosuppressive medication and to assess disease severity.

Methods Cross-sectional study hosted by the European Rare Kidney Disease Reference Network and supported by the European, Asian and International paediatric nephrology societies. Anonymised data were submitted online for any child (age $<20$ years) with COVID-19 taking immunosuppressive medication for a kidney condition. Study recruited for 16 weeks from 15 March 2020 to 05 July 2020. The primary outcome was severity of COVID-19.

Results 113 children were reported in this study from 30 different countries. Median age: 13 years (49\% male). Main underlying reasons for immunosuppressive therapy: kidney transplant (47\%), nephrotic syndrome $(27 \%)$, systemic lupus erythematosus (10\%). Immunosuppressive medications used include: glucocorticoids (76\%), mycophenolate mofetil (MMF) (54\%), tacrolimus/ciclosporine A (58\%), rituximab/ ofatumumab (11\%). 78\% required no respiratory support during COVID-19 illness, 5\% required bi-level positive airway pressure or ventilation. Four children died; all deaths reported were from low-income countries with associated comorbidities. There was no significant difference in severity of COVID-19 based on gender, dialysis status, underlying kidney condition, and type or number of immunosuppressive medications.

Conclusions This global study shows most children with a kidney disease taking immunosuppressive medication have mild disease with SARS-CoV-2 infection. We therefore suggest that children on immunosuppressive therapy should not be more strictly isolated than children who are not on immunosuppressive therapy.

\section{INTRODUCTION}

The first reports of COVID-19 from the Wuhan province showed significant differences in the outcomes between children and adult patients.
What is already known on this topic

- The severity of COVID-19 in children is significantly lower than in adults.

- The impact of immunosuppression on the severity of COVID-19 in children is unclear.

\section{What this study adds}

- Most children with kidney disease on immunosuppressive therapy who have COVID-19 experience a mild disease course.

- There is no evidence of any association between immunosuppressive medication number and the severity of COVID-19 in children.

In children, the reported mortality rates were far below $1 \%$ while in people above the age of 70 years it was above $5 \%$ or higher. It also became clear that in adult patients a number of comorbidities contributed to a worse outcome. ${ }^{12}$ Pre-existing conditions including impaired immunity, either due to a medical condition or treatment with immunosuppressive medications, were all suggested to be of importance. $^{13}$

Based on those early findings, many children taking immunosuppressive medication were advised to 'shield'. 'Shielding' as a form of social distancing is an important way to protect vulnerable people but it is also very demanding. Many authors have cautioned against its indirect 'side-effects', both physical and psychological. ${ }^{4}$ It is therefore important to accurately define the group of people who are extremely vulnerable to severe disease if infected with SARS-CoV-2.

The aim of this study was to document the severity of COVID-19 in children who were taking immunosuppressive medication due to a kidney condition.

\section{METHODS}

This was a voluntary-based survey on children with immunosuppressive treatment for kidney 
Table 1 Presenting symptoms, severity and clinical outcomes of 113 children with COVID-19 infection on immunosuppressive medication for a kidney disease

\begin{tabular}{ll}
\hline $\begin{array}{l}\text { Number of children } \\
\text { presenting with each }\end{array}$ & 73 fever (65\%) \\
symptom of COVID-19 (\%) & 35 rhinitis (31\%) \\
& 17 diarrhoea (15\%) \\
& 20 shortness of breath (18\%) \\
& 21 asymptomatic SARS-CoV-2 infection (19\%) \\
& 5 invasive ventilation (4\%) \\
Maximal respiratory support & 1 BiPAP (1\%) \\
required (\%) & 5 high-flow nasal cannula oxygen (4\%) \\
& 14 supplemental face mask oxygen (12\%) \\
& 88 none (78\%) \\
& 4 death (4\%) \\
& 2 patient on intensive care with recovery (2\%) \\
& 68 admitted to hospital (60\%) \\
& 45 not admitted to hospital at any point (40\%) \\
& 45 not admitted to hospital (grade 1) \\
& 43 admitted to hospital with no respiratory support \\
(grade 2) & \\
& 14 admitted to hospital and required supplemental \\
oxygen (grade 3) & 5 admitted to hospital and required high-flow nasal \\
cannula oxygen or BiPAP (grade 4) \\
6 admitted to intensive care or death (grade 5)
\end{tabular}

BiPAP, bi-level positive airway pressure.

disease reported to be infected with SARS-CoV-2. It was hosted by the European Rare Kidney Disease Reference Network and supported by the European, Asian and International paediatric nephrology societies. The members of these societies and the members of the PedNeph listserver were asked to include any child in their care fulfilling the inclusion criteria.

Inclusion criteria were all children $(<20$ years and under paediatric services) who have an underlying kidney disease and take immunosuppressive medication, with a diagnosis of COVID-19 (either laboratory confirmation with PCR or serology testing, or clinically highly suspected). The study was open for 16 weeks from 15 March 2020 to 05 July 2020 and included eight separate reminders sent electronically to the memberships of the above organisations.

Anonymised data were collected through an online platform including details of demographics, underlying kidney conditions, comorbidities and current immunosuppressive medication. Their symptoms at presentation were recorded, along with the method of COVID-19 diagnosis (laboratory or clinical). The severity and outcome of their COVID-19 was also reported.

Reporting authors followed their local guidance for ethical permission and information governance in reporting these data. Since all data were totally anonymised, formal ethical approval was not required in any of the centres; all reporting authors followed data governance procedures in their individual institutions.

Infection severity was graded using a 5-point scale according to clinical criteria (see table 1). Data were analysed using summary statistics and are presented as mean or median with SD and IQR or numbers with percentages. Comparisons between two groups were performed with conventional statistical tests using SPSS V.23.0.

\section{RESULTS}

Within 16 weeks from 15 March 2020 to 5 July 2020, 113 cases from 30 different countries were reported. One hundred and four cases were confirmed as COVID-19 by PCR or antibody
Table 2 Details of 113 children included in this study with kidney disease on immunosuppressive medication

\begin{tabular}{|c|c|}
\hline Median age (IQR) & 13 years ( $7-16$ years) \\
\hline Gender & $51 \%$ female, $49 \%$ male \\
\hline $\begin{array}{l}\text { Underlying kidney disease and } \\
\text { reason for immunosuppression } \\
(\%)\end{array}$ & $\begin{array}{l}53 \text { kidney transplantation }(47 \%) \\
30 \text { nephrotic syndrome }(27 \%) \\
11 \text { SLE }(10 \%) \\
7 \text { other glomerulonephritis/vasculitis }(6 \%) \\
2 \text { ANCA associated vasculitis }(2 \%) \\
2 \text { IgA Nephropathy }(2 \%) \\
2 \text { IgAVN-HSPN (2\%) } \\
2 \text { atypical HUS ( } 2 \%) \\
1 \text { C3GN }(1 \%) \\
1 \text { tubulointersitial nephritis }(1 \%) \\
1 \text { ESKD with IBD (1\%) } \\
1 \text { tuberous sclerosis }(1 \%)\end{array}$ \\
\hline Children on dialysis (\%) & $\begin{array}{l}9 \text { haemodialysis ( } 8 \% \text { ) _ four kidney transplant, } 1 \\
\text { nephrotic syndrome, } 4 \text { glomerulonephritis/ANCA } \\
3 \text { peritoneal dialysis ( } 3 \%) \text {-1 transplant, } 1 \\
\text { nephrotic syndrome, } 1 \text { IgAN }\end{array}$ \\
\hline $\begin{array}{l}\text { Coexistent pulmonary disease } \\
(\%)\end{array}$ & $\begin{array}{l}4 \text { bacterial/fungal pneumonia }(4 \%) \\
2 \text { asthma/bronchospasm }(2 \%)\end{array}$ \\
\hline Coexistent cardiac disease (\%) & 4 left ventricular dysfunction/hypertrophy (4\%) \\
\hline $\begin{array}{l}\text { Number of children on each type } \\
\text { of immunosuppression (\%) }\end{array}$ & $\begin{array}{l}86 \text { on glucocorticoids (76\%) } \\
58 \text { on tacrolimus ( } 51 \%) \\
61 \text { on mycophenolate mofetil }(54 \%) \\
11 \text { having had rituximab }(10 \%) \\
9 \text { on azathioprine }(8 \%) \\
8 \text { on ciclosporine }(7 \%) \\
8 \text { on cyclophosphamide (7\%) } \\
5 \text { on sirolimus ( } 4 \%) \\
3 \text { having had basiliximab (3\%) } \\
3 \text { on everolimus ( } 3 \%) \\
2 \text { having had ATG }(2 \%) \\
2 \text { on eculizumab ( } 2 \%) \\
1 \text { having had ofatumumab (1\%) } \\
1 \text { having had alemtuzumab (1\%) } \\
1 \text { on adalimumab (1\%) } \\
1 \text { on levamisole (1\%) }\end{array}$ \\
\hline
\end{tabular}

ANCA, Anti-neutrophil cytoplasmic antibody; ATG, antithymocyte globulin; C3GN, C3 glomerulopathy; ESKD, end-stage kidney disease; HSPN, Henoch-Schönlein purpura nephritis; HUS, haemolytic uraemic syndrome; IBD, inflammatory bowel disease; IgAN, IgA Nephropathy; IgAVN, IgA vasculitis nephritis ; SLE, systemic lupus erythematosus.

testing, the remaining nine being clinically suspected. The demographics, underlying diagnoses and current immunosuppressive treatments are given in table 2 below.

The median duration of immunosuppressive therapy before COVID-19 was 9.5 months (IQR 3-39 months). The median time from onset of illness to initial reporting was 7 days (IQR 4-15.5 days). For 55\% of included children, the authors provided an update on their clinical status to detect any long-term effects and paediatric inflammatory multisystem syndrome temporally associated with SARS-CoV-2 (PIMS-TS); the median time from illness to follow-up reporting was 43 days (IQR 29-62.5 days). Table 1 details the presenting symptoms, severity and clinical outcome of the children included in this study.

Patients with a higher infection severity (grade 4-5) were older (median 16 years, IQR 13-17) than those with lower severity (grade 1-3) with a median 12 years, IQR 6-16, but this difference was not statistically significant (OR for severe disease in those $\geq 10$ years vs $<10$ years 6.72 (95\% CI 0.83 to 54.53 ), $\mathrm{p}=0.052$ ). Infection severity did not differ by gender (OR for severe disease in males vs females 0.57 (95\% CI 0.16 to 2.07), $\mathrm{p}=0.53$ ) and dialysis status (OR for severe disease in those on dialysis vs those not 2.04 (95\% CI 0.39 to 10.81$), p=0.33$ ). 
Table 3 Comparison of COVID-19-related symptoms and outcome in 582 children from 21 European countries (78\% reported from tertiary and quaternary institutions) ${ }^{8}$ and 113 children on immunosuppression for kidney disease in our study.

\begin{tabular}{lll}
\hline & & $\begin{array}{l}\mathbf{1 1 3} \text { paediatric cases } \\
\text { on immunosuppressive } \\
\text { therapy for kidney } \\
\text { disease }\end{array}$ \\
\hline cases & $62 \%$ & $60 \%$ \\
\hline $\begin{array}{l}\text { Admitted to hospital } \\
\text { infection }\end{array}$ & $16 \%$ & $19 \%$ \\
\hline Fever & $65 \%$ & $65 \%$ \\
\hline URT symptoms & $54 \%$ & $52 \%$ \\
Gl symptoms & $22 \%$ & $15 \%$ \\
\hline $\begin{array}{l}\text { Supplemental oxygen/high-flow } \\
\text { nasal cannula oxygen }\end{array}$ & $13 \%$ & $17 \%$ \\
\hline CPAP/BiPAP & $5 \%$ & $1 \%$ \\
\hline Mechanical ventilation & $4 \%$ & $4 \%$ \\
Mortality & $1 \%$ & $4 \%(0 \%$ Europe and USA) \\
\hline
\end{tabular}

BiPAP, bi-level positive airway pressure; CPAP, continuous positive airway pressure; $\mathrm{Gl}$, gastrointestinal; URT, upper respiratory tract.

A similar distribution of disease severity was observed among kidney allograft recipients, patients with nephrotic syndrome and those with glomerulonephritis/vasculitis $(p=0.33)$. Further analyses based on the severity of infection grade are detailed in online supplementary data.

Mean serum creatinine, reported in two-thirds of children, was $114 \pm 151 \mu \mathrm{mol} / \mathrm{L}$ at first presentation, increased in the course of COVID-19 to a peak of $149 \pm 199 \mu \mathrm{mol} / \mathrm{L}$, and decreased to $98 \pm 130 \mu \mathrm{mol} / \mathrm{L}$

\section{DISCUSSION}

Our global survey of children receiving immunosuppressive treatment for kidney disease shows that the majority has a mild clinical course of COVID-19. Six children had a severe course needing ventilation and four of these children died. Notably, all fatal outcomes occurred in low-income countries.

There is now increasing evidence that children and adolescents are less susceptible to SARS-CoV-2 infection compared with adults. ${ }^{5}$ The incidence of clinically relevant SARS-CoV-2 infections is much lower in the paediatric than in the adult population and very few children die from the disease. In a UK study of 20133 patients admitted to hospital with COVID-19, only 310 (1.5\%) were below 18 years of age. ${ }^{6}$ Population-based studies have also shown that the severity of COVID-19 in children is lower than in adults. A Chinese study on 2135 children found that 112 (5.3\%) developed severe and $13(0.6 \%)$ critical disease.

A multicentre European study of 582 children from 21 different countries may provide the best comparator to our study. ${ }^{8}$ This study had $78 \%$ of its cases contributed from tertiary and quaternary institutions, therefore is likely to have been subject to similar biases as our study. Table 3 shows a comparison between that study and ours. Notably there were four deaths in the European study (case-fatality rate of $0.7 \%$ ) compared with the four deaths in our study (case-fatality rate of $3.5 \%$ ) but all deaths in our study were from low-income countries whereas none of the 74 cases from Europe and the USA took a fatal course.

In adult patients several risk factors have been described. ${ }^{6}$ Immunosuppressive treatment did not seem to be a risk factor to develop COVID-19 in 458 adult patients with an underlying rheumatological or autoimmune disease or in 159 children and young adults with nephrotic syndrome on immunosuppression. ${ }^{9} 10$
The impact of immunosuppressive therapies on COVID-19 severity is also of importance. Numerous studies have explored the disease course of adult patients on immunosuppressive treatment, with several focusing on solid organ transplant recipients. These studies include relatively small numbers and report variable outcomes. ${ }^{11}$ The reported mortality ranges from none to $28 \% .^{12-16}$ A recent study from the European Renal Association-European Dialysis and Transplant Association registry found a mortality of 20\% attributable to COVID-19 in adults with a kidney transplant. ${ }^{17}$ Data on children on immunosuppressive medication are scarce. Eight globally collected children with inflammatory bowel disease on immunosuppression all had a mild infection. ${ }^{18}$ The European multicentre study included 29 children on immunosuppressive therapy, and there was no significantly increased risk of intensive care unit admission in that cohort. ${ }^{8}$ Recent guidelines on return to school for paediatric transplant recipients highlight the lack of published data. ${ }^{19}$

Our analyses do not show any significant difference in the severity of COVID-19, based on dialysis status, underlying kidney condition or number of immunosupressant medications.

None of the children in our study were reported to have PIMSTS, the very rare syndrome which has emerged and appears to be associated with SARS-CoV-2 in children. ${ }^{20} 21$

Our study has important implications with regards to the prevention and management of COVID-19 in children taking immunosuppressive medication, the majority of whom have a mild clinical course with SARS-CoV-2 infection. At the same time, it is important to consider the indirect effects of COVID-19 on children and young people. There are numerous reports of delayed presentations to emergency departments ${ }^{22}$ and increased rates of child maltreatment. ${ }^{23}$ In addition the adverse impact of keeping children away from school should be taken into account. ${ }^{4}$ Considering all these aspects, our data support the concept that the same social distancing measures should be applied in children on immunosuppressive therapy as recommended for healthy children at a given stage of the pandemic in a country or region. Children who are in the first few months immediately post-transplant may need some stricter social distancing measures (as were in place for many centres prior to COVID-19) as published data in this small subgroup are still limited.

One limitation of our study is the potential under-reporting of milder cases leading to over-representation of severe cases. To minimise this risk, we have sent out repeated reminders to the vast majority of paediatric nephrologists around the globe. Another limitation shared with many other COVID-19 studies is the unknown number of children on immunosuppression who have asymptomatic infection and never present to healthcare units, thereby precluding a valid estimation of the true population incidence. In addition, during the first wave of the COVID-19 pandemic many children on immunosuppressive medication would have been isolating at home and off school due to concerns about their susceptibility and national 'lockdown' measures, therefore it is diffiuclt to know how many would have been exposed to SARS-CoV-2 infection.

In conclusion, our study finds that the majority of children on immunosuppression for kidney disease have a mild disease course with COVID-19. The advice to families should therefore be that children on immunosuppressive medication do not require additional strict social distancing precautions but should follow the recommendations given in their country at each given time, since there is no evidence for them to be at significantly increased risk of severe disease compared with the general population. 


\section{Author affiliations}

'UCL Great Ormond Street Institute of Child Health, University College London, London, UK

${ }^{2}$ Paediatric Nephrology, Great Ormond Street Hospital for Children NHS Foundation Trust, London, UK

${ }^{3}$ Division of Pediatric Nephrology, Heidelberg University Hospital, Heidelberg, Germany

${ }^{4}$ Driscoll Children's Kidney Center, Driscoll Children's Hospital, Corpus Christi, Texas, USA

${ }^{5}$ Pediatric Nephrology, National Medical Research Center for Children's Health, Moscow, Russian Federation

${ }^{6}$ Dr. Pinnamaneni Siddhartha Institute of Medical Sciences and RF, Vijayawada, India ${ }^{7}$ Hopital Universitaire Robert Debre-APHP, Paris, France

${ }^{8}$ Service de Néphrologie pédiatrique, Centres de référence MARHEA et SNI, Université de Paris, Inserm U1163, Hôpital Necker-Enfants malades, AP-HP, Paris, France

${ }^{9}$ Pediatric Nephrology Transplant Department, G.Almenara Hospital, Lima, Peru ${ }^{10}$ Department of Paediatric Nephrology, Mehta Multispecialty Hospitals, Chennai, India

${ }^{11}$ Aliasghar Clinical Research Development Center, Aliasghar Children hospital, Iran University of Medical Sciences (IUMS), Tehran, Iran (the Islamic Republic of

${ }^{12}$ Children's Kidney Centre, King Edward Medical University, Mayo Hospital, Lahore, Pakistan

${ }^{13}$ Nephrology Paediatric Unit, Department of Pediatrícs, Cayetano Heredia National Hospital, Lima, Peru

${ }^{14}$ Pediatric Nephrology Department, La Paz University Hospital, Madrid, Spain ${ }^{15}$ Department of Pediatrics, Topiwala National Medical College \& B. Y. L. Nair Charitable Hospital, Mumbai, India

${ }^{16}$ Department of Paediatrics II, University Hospital Essen, Essen, Germany

${ }^{17}$ Pediatric Nephrology, Institute Of Kidney Diseases And Research Center And

Institute Of Transplantation Sciences (IKDRC-ITS), Ahmedabad, India

${ }^{18}$ New York Medical College, Valhalla, New York, USA

${ }^{19}$ Radboudumc Amalia Children's Hospital, Nijmegen, Netherlands

${ }^{20}$ King Edward Memorial Hospital, Pune, India

${ }^{21}$ Baylor College of Medicine, Texas Children's Hospital, Houston, Texas, USA

${ }^{22} \mathrm{ICH}$, Institute of Child Health, Kolkata, India

${ }^{23}$ Dwaine \& Cynthia Willet Children's Hospital, Savannah, Georgia, USA

${ }^{24}$ Paediatric Nephrology, University Children's Hospital, Skopje, North Macedonia

${ }^{25}$ Department of Pediatrics I, University Children's Hospital, Heidelberg, Germany

${ }^{26}$ Medical University of South Carolina, Charleston, South Carolina, USA

${ }^{27}$ Division of Pediatric Nephrology, University of Florida, Gainesville, Florida, USA

${ }^{28}$ Division of Nephrology and Dialysis, Department of Pediatric Subspecialties, IRCCS Bambino Gesù Children's Hospital, Rome, Italy

${ }^{29}$ Division of Pediatric Nephrology and Hypertension, Atrium Health Levine Children's, Charlotte, North Carolina, USA

${ }^{30}$ Stony Brook Children's Hospital, New York City, New York, USA

Twitter Samhar Al-Akash @al_samhar, Olivia Boyer @NeckerNephroPed and Sukanya Govindan @GovindDrsuk

Acknowledgements The authors thank all colleagues who contributed cases to this survey: Sabah Abbas Alsannaa, Ma. Angeles G. Marbella, Gema Ariceta, Paula Soledad Bresso, Kathrin Buder, Maria Rosario Cabansag, Paula Alejandra Coccia, Lesa Dawman, Filipa Durão, Elizabeth Ingulli, Chryso Pefkaros Katsoufis, Deborah Kees-Folts, Noël Knops, Kevin V Lemley, Kenneth Lieberman, Jacques Lombet, Javier Lumbreras, Adrian Catalin Lungu, Laura Malaga-Dieguez, William Morello, Damien Noone, Paloma Parvex, Ketan N Patel, Viola M Pinto, Helen Pizzo, Ann Raes, Ben C Reynolds, Jyoti Singhal, Jodi Smith, Jelena Stojanovic, Sara Testa, Susan Uthup, Darcy Weidemann, Patricia L Weng, Katherine D Westreich.

Contributors KT, FS, MM and TW devised the idea for the study, KT, FS, MM, TW, LP, BT and MV planned the study set-up and coordinated the study data collection. All authors contributed to study data collection and reviewing of the manuscript to be published. All authors have reviewed the manuscript and all those named in the acknowledgements have given written consent to do so. MM had full access to all the data in the study and takes responsibility for the integrity of the data and the accuracy of the data analysis.

Funding This survey has been supported by European Rare Kidney Disease Reference Network (ERKNet). ERKNet is co-funded by the European Union within the framework of the Third Health Programme 'ERN-2016 Framework Partnership Agreement 2017-2021'.

Competing interests None declared.

Patient consent for publication Not required.

Provenance and peer review Not commissioned; externally peer reviewed.

Data availability statement Data are available upon reasonable request.
Supplemental material This content has been supplied by the author(s). It has not been vetted by BMJ Publishing Group Limited (BMJ) and may not have been peer-reviewed. Any opinions or recommendations discussed are solely those of the author(s) and are not endorsed by BMJ. BMJ disclaims all liability and responsibility arising from any reliance placed on the content. Where the content includes any translated material, BMJ does not warrant the accuracy and reliability of the translations (including but not limited to local regulations, clinical guidelines, terminology, drug names and drug dosages), and is not responsible for any error and/or omissions arising from translation and adaptation or otherwise.

Open access This is an open access article distributed in accordance with the Creative Commons Attribution Non Commercial (CC BY-NC 4.0) license, which permits others to distribute, remix, adapt, build upon this work non-commercially, and license their derivative works on different terms, provided the original work is properly cited, appropriate credit is given, any changes made indicated, and the use is non-commercial. See: http://creativecommons.org/licenses/by-nc/4.0/.

\section{ORCID iDs}

Matko Marlais http://orcid.org/0000-0001-7503-7893

Velibor Tasic http://orcid.org/0000-0002-3377-1245

Kjell Tullus http://orcid.org/0000-0003-3706-7375

\section{REFERENCES}

1 Zhou F, Yu T, Du R, et al. Clinical course and risk factors for mortality of adult inpatients with COVID-19 in Wuhan, China: a retrospective cohort study. Lancet 2020:395:1054-62

2 Verity R, Okell LC, Dorigatti I, et al. Estimates of the severity of coronavirus disease 2019: a model-based analysis. Lancet Infect Dis 2020:20:669-77.

3 Guan W-J, Liang W-H, Zhao Y, et al. Comorbidity and its impact on 1590 patients with COVID-19 in China: a nationwide analysis. Eur Respir J 2020;55:2000547.

4 Green P. Risks to children and young people during covid-19 pandemic. BMJ2020:m1669.

5 Viner RM, Mytton OT, Bonell C, et al. Susceptibility to SARS-CoV-2 infection among children and adolescents compared with adults: a systematic review and metaanalysis. JAMA Pediatr 2020:1-14.

6 Docherty AB, Harrison EM, Green CA, et al. Features of 20133 UK patients in hospital with covid-19 using the ISARIC WHO Clinical Characterisation Protocol: prospective observational cohort study. BMJ 2020:m1985.

7 Dong Y, Mo X, Hu Y, et al. Epidemiology of COVID-19 among children in China. Pediatrics 2020;145:e20200702

8 Götzinger F, Santiago-García B, Noguera-Julián A, et al. COVID-19 in children and adolescents in Europe: a multinational, multicentre cohort study. Lancet Child Adolesc Heal 2020;4642:1-9

9 Emmi G, Bettiol A, Mattioli I, et al. SARS-CoV-2 infection among patients with systemic autoimmune diseases. Autoimmun Rev 2020;19:102575.

10 Angeletti A, Drovandi S, Sanguineri F, et al. COVID-19 in children with nephrotic syndrome on anti-CD20 chronic immunosuppression. CJASN 2020:1-2.

11 Bossini N Alberici F, Delbarba E, et al. Kidney transplant patients with SARSCoV-2 infection: the Brescia renal COVID Task force experience. Am J Transplant 2020:ajt. 16176

12 Ketcham SW, Adie SK, Malliett A, et al. Coronavirus Disease-2019 in heart transplant recipients in southeastern Michigan: a case series. J Card Fail 2020;26:457-61.

13 Fernández-Ruiz M, Andrés A, Loinaz C, et al. COVID-19 in solid organ transplant recipients: a single-center case series from Spain. Am J Transplant 2020;20:1849-58.

14 Pereira MR, Mohan S, Cohen DJ, et al. COVID-19 in solid organ transplant recipients: initial report from the US epicenter. Am J Transplant 2020;20:1800-8.

15 The Columbia University Kidney Transplant Program. Early description of coronavirus 2019 disease in kidney transplant recipients in New York. JASN 2020;31:1150-6.

16 Banerjee D, Popoola J, Shah S, et al. COVID-19 infection in kidney transplant recipients. Kidney Int 2020;97:1076-82.

17 Jager KJ, Kramer A, Chesnaye NC, et al. Results from the ERA-EDTA registry indicate a high mortality due to COVID-19 in dialysis patients and kidney transplant recipients across Europe. Kidney Int 2020:1-9.

18 Turner D, Huang Y, Martín-de-Carpi J, et al. Corona virus disease 2019 and paediatric inflammatory bowel diseases. J Pediatr Gastroenterol Nutr 2020;70:727-33.

19 Downes KJ, Danziger-Isakov LA, Cousino MK, et al. Return to school for pediatric solid organ transplant recipients in the United States during the coronavirus disease 2019 pandemic: expert opinion on key considerations and best practices. J Pediatric Infect Dis Soc 2020:1-13

20 Dufort EM, Koumans EH, Chow EJ, et al. Multisystem inflammatory syndrome in children in New York state. N Engl J Med Published Online First 2020.

21 Feldstein LR, Rose EB, Horwitz SM, et al. Multisystem inflammatory syndrome in U. S. children and adolescents. N Engl J Med 2020:1-13.

22 Lazzerini M, Barbi E, Apicella A, et al. Delayed access or provision of care in Italy resulting from fear of COVID-19. Lancet Child Adolesc Health 2020:4:e10-11.

23 Sidpra J, Abomeli D, Hameed B, et al. Rise in the incidence of abusive head trauma during the COVID-19 pandemic. Arch Dis Child 2021;106:e14 